\title{
EDITORIAL
}

\section{Preparing for the Lurch into a Surgery Clerkship}

\author{
Curt Tribble, $\mathbf{M D}^{1}$, Dustin Walters, $\mathbf{M D}^{2}$
}

${ }^{1}$ Division of Cardiac Surgery, and ${ }^{2}$ Division of Thoracic Surgery, University of Virginia Health System, Charlottesville, Virginia, USA

\section{INTRODUCTION}

Over our combined nearly 50 years as surgical educators, we have been asked many times by medical students how they should prepare for and function in a Surgery Clerkship. It is still easy for me (C.G.T.) to recall, as a medical student myself, having the same questions. While I had initially thought that the transition from college to medical school would be challenging, I quickly realized that the first few years of medical school were not as much of a transition as I had imagined. However, as the clerkship year approached for my medical school classmates and me, it was quite clear to us that we were about to enter an educational environment for which our prior years in college and medical school had likely not optimally prepared us. And, when the primary advice we were given about how we should function as medical students rotating through the clerkships was that we should "just live the life of the house officer," we realized that we had little to no idea what we were actually supposed to do once we began the clerkship year.

After somehow making my way through the clinical years of medical school, residencies in General Surgery and in Thoracic and Cardiovascular Surgery, followed by joining the faculty of the Department of Surgery at the University of Virginia, I was asked to become the Program Director of the Surgery for the General Surgery Residency, as well as the Director of the Surgery Clerkship, positions I held for many years thereafter. I realized that I wanted to be able to provide a better answer for my students about how to approach their clerkships than I myself had been given. Now, I will hasten to say, in retrospect, that the validity of the advice I was given, "to live the life of the house officer," turned out to be more appropriate than I had at first thought. Still, I knew that providing more granular advice to students starting clerkships, especially the Surgery Clerkship, would be helpful.

One of the first epiphanies I had when trying to formulate useful advice to medical students preparing to start the

Correspondence: Curt Tribble, MD, Professor of Cardiothoracic Surgery, University of Virginia Health System, Division of Cardiac Surgery, Box 800679, Charlottesville, VA 22908; 434-243-9250 (e-mail: ctribble@ virginia.edu).
Surgery Clerkship was that they all needed to know why every future physician needed to have the experiences that are encompassed in a Surgery Clerkship. Most students also need some advice about how to get the most out of that experience, including how to study and learn during the Surgery Clerkship. Finally, the students needed to realize that at least a small percentage of them may end up wondering if a surgical discipline might be an appropriate career trajectory for them.

Therefore, in this treatise, my co-author (D.M.W., a former student and current faculty colleague) and I (C.G.T.) will attempt to convey some strategies that medical students rotating on surgical services in the clerkship year can employ to address these 4 objectives. While many of these strategies are applicable to clerkships in all disciplines, we will orient the advice and suggestions primarily towards those entering a Surgical Clerkship. Therefore, we will attempt to provide some answers to the following questions:

- Why does every future physician need to study surgery?

- How can one get the most out of a Surgery Clerkship?

- What are some tips for "learning on the go" in a Surgery Clerkship?

- How might one decide if a surgical career is a good fit?

\section{WHY DOES EVERY FUTURE PHYSICIAN NEED} TO STUDY SURGERY?

If you know the why, you can figure out the bow. - John Douglas, The Anatomy of Motive

While less than $10 \%$ of all medical students will choose to train in General Surgery, there are many things to which all medical students will need to be exposed during their Surgery Clerkships, because every physician needs to have at least some understanding of surgical issues. In fact, a Surgery Clerkship might be most accurately described as "Surgery for Primary Care Physicians."

First of all, almost everyone will need an operation at some point in their lives, including almost all of one's future patients, as will most physicians and most in their families. Furthermore, every doctor needs to understand the following: 
- How to deal with the anxiety patients have when facing procedures

- Obtaining informed consent for procedures

- The care of the unconscious patient

- The early diagnosis of the acute abdomen

- Basic principles for performing procedures

- The "germ theory" (principles of sterility)

- Proper wound care

- Dealing with acute pain

- How to work efficiently in teams of health care providers

- The importance of active and closed loop communication

And, perhaps the most important concept that will be learned during a Surgery Clerkship is the role of a primary care physician in diagnosing conditions that may require referral to a surgeon. Furthermore, if an operation is planned, the primary doctor will likely need to help prepare the patient for that event, both medically and psychologically. In addition, the referring physician will frequently play an important role in that patient's care after the operation, including managing pain, evaluating wounds, and helping with other aspects of recovery once the patient has left the hospital.

Next, it is worth acknowledging that there are many aspects of medicine that are primarily managed by surgeons (though almost always in collaboration with their medical colleagues), including the following:

- Trauma

- Vascular disease

- Congenital defects

- Device implantation

- Endocrine disorders

- Transplantation

- Cancer operations (We note that more than half of all cancers that are cured are cured in an operating room.)

It is also pertinent to recognize that health care in certain arenas almost always involves surgical procedures, and those arenas include the following:

- Work in the mission field

- Military medicine

- Provision of health care in areas with limited resources

- Disaster relief work

Furthermore, each third-year clerkship will provide at least some insight into what aspect of medicine you might choose for your career, and we will cover some aspects of how to go about deciding if a career in Surgery might be a good fit for you.

Not all doctors think alike. - Jerome Groopman, How Doctors Think

Beyond the clinical exposures of a Surgery Clerkship, medical students will also learn how surgeons think, not only about diagnoses and procedures, but also about the ways in which they analyze things that have not gone well (Surgical Intuition [Abernathy 1995]).

Although analysis of outcomes has become more common in all medical specialties in recent years, regular Morbidity and Mortality conferences have been a core aspect of surgical disciplines for generations (A Practical Minded Obsession [Tribble 2016a]). Every medical student will be exposed to and need to understand the "fierce ethic" of the analyses that are conducted in these conferences [Gawande, When Doctors Make Mistakes].

Understanding how surgeons think is a particularly important objective during a Surgical Clerkship. There is often a misconception that surgeons are merely technicians. There is, perhaps, some truth to this belief. However, the art of surgery lies in the integrating of pathophysiology with surgical risk assessment and examining it all through the lens of each patient's personal narrative. In essence, the art of surgery, like many areas of medicine, is thoughtfulness. Knowing when not to operate is often the most important lesson that can be learned. These are the lessons that are regrettably absent from surgical textbooks and preclinical lectures and, therefore, must often be gleaned from clinical exposure combined with careful observation and contemplation.

Perhaps the most succinct summary of reasons that all medical students need to experience a Surgery Clerkship is contained in the old admonition that the next time you see any given scenario, someone's life may hang in the balance, and, because of this exposure, you may have at least some idea of what can and should be done for that patient [Meador 2013].

\section{HOW CAN YOU GET THE MOST OUT OF A SURGERY CLERKSHIP?}

It was all the same dream about being in a locked room. And, like a lot of dreams, there was a monster at the end of it. - Matthew McConaughey (as Rust Cohle) in True Detective

Some medical students, especially those who have not had much, if any, prior exposure to surgery, may think that their experience on a Surgery Clerkship will be like an episode of the popular television series, True Detective: eerie, hard to follow, and puzzling. Perhaps a more common feeling that many medical students will have prior to starting a Surgery Clerkship is the combination of awe and anxiety they experienced when starting into Gross Anatomy early in medical school. However, there are many approaches that can be taken by medical students to survive, and even thrive, while on a Surgery Clerkship. And, it helps to understand that the experience of a Surgery Clerkship not only can be very educational but also can be very engaging.

One of our favorite senior surgical residents, when orienting new medical students to his surgical teams, likes to point out 3 things:

- This rotation will be hard, not just because the hours are long, but also because it will not be like any of your prior rotations.

- While the surgical services can run smoothly without medical students, each student can, and should, strive 
to contribute to the overall mission of the service, as well as to the care of their own patients.

- $\quad$ Every student should show up with enthusiasm and a sense of engagement for this and all clerkships, taking the attitude that you might end up wanting to train in each of them.

Another of our senior surgical residents likes to tell his new students:

- You may sometimes feel like an outsider. However, everyone else on the team understands the somewhat awkward situation you are in and will help you contribute to the mission of the team.

- You will find that all student clerkship rotations feel like speed dating with a bunch of folks with personality disorders, but you need to understand the stress that the residents and the faculty are regularly experiencing.

- You should take ownership of your patients. They are real people who will appreciate, and benefit from, your care and attention. MD

You either pull freight or you are freight. —Lorne Blackbourne,

How can you, as a medical student, in addition to optimizing learning, also contribute to the work of the service and to the care of the patients?

First of all, you must have a good attitude. The way you talk is an integral part of the way you work and learn. You should strive to use the language of commitment, while avoiding the language of complaint. A great example of this language of commitment is the statement made by Blue Angels pilots at each debriefing after a performance, which is "It's a privilege to be here." You, as a student, should always remember what a privilege it is to be part of a medical or surgical team caring for patients (The Way We Talk [Tribble 2014]).

Second, you must look the part. As the old saying goes, you should dress to inspire confidence. You cannot look like you just came in from a run. That means you need to dress neatly and professionally. You should wear a white coat over professional attire. And, you should not wear running shoes, especially gaudy or dirty ones. After all, patients in a teaching hospital cannot choose all of their providers, a reality that adds even more importance to these issues.

\section{Your soul will be enriched by each person you care for. - Thomas Nasca, CEO of ACGME}

Next, you need to understand "the main doctor concept," which means that you can, and should, attempt to function as the primary doctor for the patients to whom you are assigned. This approach is good for everyone involved. The patients will benefit from, and generally enjoy, the attention that you give them. We like to tell medical students that there are 3 things they can do in their interactions with their patients which we call "The Three Steps:"
- Things you can say (introduce yourself as a student who has been asked by the attending surgeon to help with their care)

- Things you can ask (find out what the patient wants to do when they are well again)

- Things you can do (get things for them like a drink or a warm, wet washcloth or find out answers to their questions) (Gimme Three Steps [Tribble 2016b])

Start where you are. Use what you have. Do what you can. Arthur Ashe, former Wimbledon Champion

Students can also help with the efficient functioning of the surgical team, including gathering information (such as labs, pathology reports, radiology reports, and descriptions of wounds), helping with procedures (such as suture or staple removal or dressing changes), and participating in the day-to-day clerical work (writing, or at least helping to write, admission histories and physicals, procedure notes, or progress notes). Students should always examine their own patients each day, which can be educational and helpful to the team caring for the patients (The M4-PGY-1 Lurch, [Tribble 2018]).

After all, getting comfortable with the process of examining patients takes practice and repetition. These skills can only be learned by observing and doing them. Therefore, when you have the privilege of examining your patients, take the opportunity to do so.

All students on surgical rotations will be expected to be in the operating room on a regular basis. You should ask your residents which cases you should scrub on or observe. You can learn a lot by observing surgical procedures, even without being scrubbed. If you are not actually scrubbed and at the operating table, find operating room stools, so that you can stand behind the surgeons and look over their shoulders. Of course, if some sort of scope is being used, with images displayed on a screen, you will have an even better view of what is going on. Observing how the surgeons handle tissue with care, identify anatomy, grasp their instruments, and efficiently move through the steps of an operation will contribute to an important foundation, particularly if you eventually decide to pursue a career in a surgical discipline.

The operating room is also an important opportunity to observe how effective teams work together. Nurses, surgeons, trainees, anesthesiologists, and other adjunct staff members must work in concert to solve challenging clinical problems in the operating room. And, operations are unique occasions to observe how these team members communicate, using what's known as "closed loop communication," confirming the receipt and understanding of information as it is delivered.

If you have not had a chance to be in an operating room prior to your clerkship, there are many basics of operating room etiquette that may seem unfamiliar, even when you have had the orientation to the operating room commonly provided to medical students. One of the best, but succinct, outlines of these issues is provided in the first chapter of Surgical Recall [Blackbourne 2018], so we will not review them here. However, it is important to note that you should introduce yourself to the operating room staff, well in advance of the patient entering the 
operating room. Showing the operating room staff respect will pay enormous dividends.

The eye does not see what the mind is not prepared to know. Clifton Meador, Fascinomas

You should always prepare properly for the cases that you expect to observe or participate in. Know the anatomy. Look up the operations in books or online so that you will have some idea of how the operation is likely to proceed. For many operations, especially minimally invasive ones, there are excellent narrated videos available online. One of the best ways to anticipate questions you may be asked is to read about the procedure in Surgical Recall.

You should plan to get to the operating room early, if at all possible. First of all, being on time, or even being early, will make a good impression. Second, you may get a chance to perform procedures such as placing catheters or intravenous lines. You may also be able to help by doing things like getting radiological images pulled up on a viewer. You may even be able to help during the operation by providing an extra set of hands for retraction, or more, once you have demonstrated interest and at least a modicum of aptitude. You can, and should, ask questions about things you do not understand, though you do need to have, or develop, some sense of when, in the rhythm of the case, it is appropriate to ask questions.

Everyone in this room will have a different view of what is going on. If you see something, say something. - M.C. Wilhelm, MD

One of my (C.G.T.) favorite mentors, Dr. M.C. Wilhelm, used to announce at the beginning of every operation, that he wanted everyone in the room to speak up if they saw something that might be important, since, as he always noted, everyone present will have a different view of what is going on and, therefore, might see something important that the primary surgeons are not seeing in the same way. A good example of how the untrained eye might see something that others miss is illustrated by the FedEx logo:

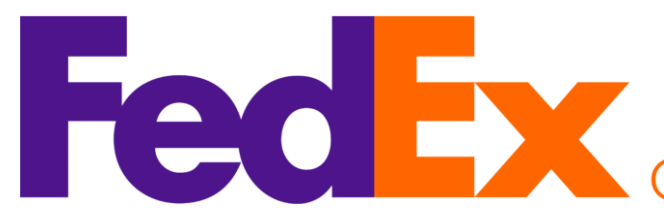

Children who cannot read generally see the white arrow while those who can read tend not to see the arrow while reading the actual words in this logo.

A few other practical suggestions may be helpful. It should be obvious, but it is worth reminding yourself to head to a restroom prior to starting a case. You will, of course, want to wear comfortable shoes, and some find it helpful to wear support stockings or even to wrap their lower legs with elastic wraps, particularly for longer cases. Finally, remember that it is likely that you will never get the chance to have this degree of involvement in an operation in the future, unless you choose to enter a surgical field. Therefore, you should take advantage of as many of these very educational opportunities as you can.

\section{THE DAYS ARE JUST PACKED: LEARNING ON THE GO}

To achieve great things, two things are needed: a plan and not quite enough time. - Leonard Bernstein, former Director of the New York Philharmonic

One of the most challenging aspects of training in clinical medicine, as either a student or a resident, is that most, if not all, of your prior educational practices and strategies will not serve you very well, given the pace of the days and the time constraints of working on the wards, in the clinics, and in the operating rooms. Therefore, to be effective as a clinical student, your educational paradigms will have to evolve beyond the strategies you used in college and in the first 2 years of medical school.

First of all, when faced with taking in a lot of new information in a short time, it is essential to have a matrix or overview of what you will be exposed to (The M4-PGY-1 Lurch [Tribble 2018]). I have often likened this concept to mailboxes in a mailroom, into which bits of information can be inserted as one encounters them. One way to "create" this matrix is to obtain an introductory textbook, such as Essentials of General Surgery edited by Peter Lawrence [Lawrence 2013]. While it would, indeed, be a tall order to attempt to read thoroughly even an introductory textbook like this one early in the clerkship, one can begin the process by skimming the introductions to the chapters. This approach can at least begin to give you a sense of what you will see and hear on the clerkship. One trick that can make this process more expeditious is to have the spine (the back) of the book cut off in a copy center and to have holes drilled in the pages so that they can be kept in a 3-ringed notebook. Then, a fistful of pages can be taken out of the notebook and carried around to peruse during the scraps of time that are a frequent part of all but the busiest days on a surgical service. Another popular, and even more succinct, book that can serve as an introduction to surgical services is Dr. Pestana's Surgery Notes, written by the engaging author and surgical educator, Dr. Carlos Pestana [Pestana 2015].

Furthermore, given that virtually every clerkship will conclude with a "shelf exam," you must read at least somewhat broadly during each clerkship. Therefore, it is prudent to make a plan to have covered most of an appropriate textbook during the course of each clerkship. From a practical standpoint, that means that you will need to assign yourself a certain number of pages of that book to be covered on a daily basis, with a plan to catch up, eventually, if you miss your quota for a given day.

The second priority should be to read about the patients for whom you are caring. It is essential to read prior to all cases in which you will participate. You will be expected to know at least some basic information about these cases, including the indications for the operations and the anatomy that is likely to be encountered. UpToDate can be very helpful in this setting. This 
resource is an online system that is described as "a point-of-care medical resource" and is considered an evidence-based clinical reference. Many medical libraries subscribe to this resource. This type of study is, obviously, very efficient, as you will remember the material you cover for a specific case much better than the material you read in a more random fashion.

Another helpful approach is to have some idea of what questions you will be asked on rounds, in clinics, and in the operating rooms. Again, one of the best collections of such questions is Surgical Recall. In contrast to collections of multiple choice questions, this book consists of questions followed by succinct answers, which is analogous to the Socratic questioning style of most teachers of clinical medicine and surgery. Of course, it is also possible to utilize other online resources to be reminded of the anatomy you are expecting to see in an operation and to learn about the specific procedure that is planned.

An old principle holds that writing increases learning. And, it is almost certainly better to write notes by hand, rather than to type them. Studies using functional MRI have shown that 3 parts of the brain light up with handwriting, while only 1 part of the left hemisphere is engaged when one types (In Your Own Words [Tribble 2016c]). One efficient way to take notes at conferences or to write reflective notes on cases in which you have participated is to have a small notebook with you at all times. You can write down questions or scraps of information as they arise during the day. You should review these notes to solidify your memory of them and to remind yourself of things you might delve into more deeply when you have a chance. And, when a deeper "dive" reveals something interesting, you can share that additional information with your peers and residents. After all, there is truth to the old adage that "to teach is to learn twice." Another strategy that has been dubbed "the 30 second habit" consists of taking 30 seconds after a learning opportunity such as a case, an interesting patient, or a lecture or chalk talk to consolidate your thoughts and to make notes of things that you will look up or review later (The M4-PGY-1 Lurch [Tribble 2018]).

\section{BEING HELD FOR QUESTIONING}

The hard part about being a bartender is figuring out who is drunk and who is just stupid. — attributed to Richard Braunstein

It is, of course, inevitable that you will be tested at the end of each clinical clerkship, including a Surgery Clerkship. These tests are described as "shelf exams," and they are similar to the questions you will see on part II of the National Board of Medical Examiners (NBME) exam. While the precise content of the shelf exams in any given year is a fairly closely guarded secret, even to your teachers, it is worth noting that the majority of the questions will come from the broad category of General Surgery, while a relatively small minority will be based on topics in the surgical specialties and subspecialties. Thus, you must focus most of your reading and studying on General Surgery. Some educators also strongly recommend studying simple questions with simple answers rather than multiple choice questions when preparing for exams of this sort. Again, Surgical Recall is one excellent source of these simple questions and answers. The idea behind this recommendation is that you need to know the "just right answer" to the question so that, when taking a multiple choice test, you can look for that answer "disguised" in the multiple answers provided.

\section{LAGNIAPPE}

As an aside, you, as a third-year medical student, cannot get caught up in trying to be your own family's doctor, regardless of how tempting it may be to try to fill this role, especially if the family member receiving care elsewhere is a relatively distant relative. First of all, you are not a doctor, at least not yet. Second, you do not have the time to take on such a role, as your absolute top priority must be to stay completely engaged with your medical education. Third, trying to be a family doctor for someone far away often just muddies the water for that patient and those directly caring for that person. And, if you perform poorly on your rotations and exams because of distractions of this sort, those reviewing your record for residency applications will not care why your performance in your clerkships was not optimal. Thus, if distractions of this sort prevent you from doing your best job on your rotations and on your exams, your career options may be compromised to a significant degree. However, if the family member who is having health problems is a close family member, and your attention or presence is truly needed, consider taking an official leave of absence to help with that person's care.

\section{SO YOU WANT TO BE A SURGEON}

Everyone wants to be a surgeon. I can prove it. Walk into any hospital and say to the first person that you see, "You look like a surgeon. Can you tell me the way to the operating room?" Each person you ask will give you those directions but no one will deny being a surgeon. -L.D. Britt, MD

Even if Dr. Britt's humorous assertion is true, it is a fact that only about $10 \%$ of medical students in the United States need to go into General Surgery or its specialties to fill all the available training slots. Still, that does mean that over a thousand U.S. medical students will choose to enter a categorical General Surgery residency.

\section{It's not often easy, and not often kind}

Did you ever have to make up your mind? Mind?

-The Lovin' Spoonful, Did You Ever Have to Make Up Your

A lot of medical students change their minds about what type of training they want to pursue based on their experiences during the clerkship year. Many come to medical school thinking that they will want to train in disciplines such as orthopedics or family medicine, which is likely because those are the types of doctors with whom they had interacted while growing up. However, once they see the full spectrum of the various disciplines, they very frequently become interested in other career paths. 


\section{THE CAREER DECISION "FLOWCHART"}

This is the dawning of the rest of our lives ... - Green Day, Holiday

Over the many years that we have contemplated how medical students, ourselves included, approached their choice of a career, we have come to believe that a "timehonored" paradigm that many believe underlies these decisions may not be accurate. Specifically, many who advise medical students on choosing a career say that the first "branch" in the career-decision algorithm is to decide whether the student wants to have "deep and abiding" relationships with his or her patients.

Of course it's hard. It's supposed to be hard. If it wasn't hard, everyone would do it. The hard is what makes it great. - Tom Hanks (as Jimmy Dugan) in A League of Their Own

However, we believe that another factor may take precedence for many students, and that factor is whether the future physician wants to take care of sick patients or wants to care for patients who are primarily well. In general, we make no "value judgements" about which career choice is better or more laudable. In medicine, we need plenty of physicians practicing in both realms. Students who find themselves drawn to learning how to care for patients who are, or could be, mortally ill, will find themselves considering a fairly broad array of training paradigms, from Internal Medicine and many of its subspecialties, to Pediatrics and some of its subspecialties, Emergency Medicine, Anesthesiology, or Surgery and many of its subspecialties. Those who are not drawn to caring for the seriously ill will tend to be drawn towards Family Medicine, General Internal Medicine, General Pediatrics, Obstetrics and Gynecology, and Radiology (and some of the subspecialties of these disciplines). To be complete, it is certainly worth noting that most disciplines have subspecialties in which very ill patients will be cared for, especially in the critical care aspects of those disciplines. One reward that most procedurally based practitioners enjoy is seeing an immediate, or relatively immediate, improvement in the condition of at least some of their patients.

We believe that the next step in the career-choice algorithm is to decide whether one is drawn to disciplines that involve procedures of one sort or another. Again, there are technically oriented niches in Internal Medicine, Pediatrics, and, of course, Obstetrics and Gynecology, including the sub-specialties involving interventional procedures, such as cardiology, gastroenterology, interventional radiology, and surgical procedures, such as Gynecological Oncology.

Surgery is high risk and high reward. The intensity, immediacy, and power of the operating room harness an excitement and intrigue that is singular in medicine. At the same time, surgery is punctuated with moments of high anxiety and stress. Robert Swendiman, MD, Amy C. Edmondson, PhD; Najjia N. Mahmoud, MD [Swendiman 2019]
When contemplating whether a procedurally based discipline is a good fit, there are several considerations, which include the facts that training in such disciplines requires significant additional training time and that technically oriented disciplines require some physical and psychological traits that some students will think of themselves as having while others will believe these traits are not among their strengths. The requirements of procedurally oriented disciplines generally include the following:

- Binocular vision (without which one has impaired depth perception)

- Two hands

- And, the psychological makeup to be able to deal with failure (because failure is an inevitable part of procedural-based medical care) (A Practical Minded Obsession [Tribble 2016a]).

If one believes that one has these attributes, choosing to enter a procedurally based discipline may be reasonable.

Another basic question to pose to students asking for advice while making decisions about their future training options is: where do you get your energy? If a student knows that they have enjoyed learning about and doing technical things, from arts and crafts or woodworking to being a shade tree mechanic or an athlete, then a procedurally based discipline might be a good fit for that person.

This concept is illustrated by a colorful exchange one of us (C.G.T.) overheard between a third-year medical student and a senior surgical resident, as the resident was writing a post-op note in a chart:

Student: Dr. R, how do you know if [the discipline of] surgery is right for you?

Resident (without looking up): Have you ever been sunburned?

Student: Yep....

Resident: Sunburned enough to have skin that peeled?

Student: Yea. ...

Resident: Did you peel the sunburned skin?

Student: Well, yes....

Resident: Did your mouth water?

Student: Yes, it did. . . .

Resident: Well then, you could be a surgeon!

As funny as this conversation was to hear, I do believe that the senior resident had colorfully illustrated one of the most important things that a student needs to consider in choosing a career. If you get energy from doing things, 
you will have the energy to train in surgery or a procedural discipline. After all, training trajectories in surgical and procedural disciplines are longer, usually by several years, than are disciplines that are not procedural, and one must, therefore "get energy back" from doing things.

Another window into deciding on a career trajectory is to make observations about potential role models. Do the practitioners in the fields you are considering seem to be people you could, or might like to, emulate? However, this approach to choosing a discipline in which to train needs to be a nuanced one. For instance, sometimes practitioners in a particular field who are somewhat different from their colleagues are those who are actually considered the most successful or who are the leaders in their respective fields. Perhaps the optimal "alignment of the stars" comes from considering whether those you admire and those who seem most satisfied are enough like you to make it seem plausible that you could follow in their footsteps.

As an aside, you should not worry if you find that you have enjoyed most of your clerkships, as I believe that the best doctors do tend to be those that enjoyed all of their clinical experiences. In fact, we have found that good comments and grades in most of the clerkships are among the best predictors of superior performance in a surgical residency.

In summary, although almost any medical student can consider a surgical career, becoming a surgeon is not for everyone.

\section{CONCLUSIONS}

Many medical students approach their Surgery Clerkships with at least some apprehension, and that is especially true for those who think that Surgery or a surgical discipline will not likely be in their career plans. However, most students, especially if properly prepared and oriented, will find their experiences on these services to be not only more educational than they had anticipated but to also be more enjoyable. .

I expected an ordeal. But I knew that it would be an ordeal of grandeur. —Webb Chiles, Storm Passage [Chiles 1977]

As is true in so many endeavors, each of us will get the most out of experiences that we put the most into. Therefore, we firmly believe that each medical student should approach each new clerkship experience with an open mind, with a commitment to learning as much as possible, and with a willingness to contribute to the work of their clinical teams in the care of their patients. A commitment to this approach will benefit both you and your patients, as well as all others involved in the care of these patients. And, with the proper mindset, the experience will likely be a grand one.

\section{ACKNOWLEDGMENTS AND DISCLAIMER}

Disclaimer: The study guide mentioned in this treatise, Surgical Recall, was originally created at the University of Virginia, inspired and guided by Dr. Lorne Blackbourne. The authors have no commercial involvement with this publication.
Acknowledgments: Many students, residents, and colleagues, past and present, contributed to the content of this article. Several were particularly helpful, including John Davis, Eric Charles, Hunter Mehaffey, Reid Tribble, and David Robaczewski.

\section{REFERENCES}

Abernathy C, Hamm R. 1995. Surgical intuition: what it is and how to get it. Philadelphia: Hanley \& Belfus.

Blackbourne L. 2018. Surgical recall. 8th ed. Philadelphia: Lippincott, Williams \& Wilkins.

Chiles W. 1977. Storm passage: alone around Cape Horn. New York: New York Times Book Company.

Douglas J, Olshaker M. 1999. The anatomy of motive. New York: Simon \& Schuster.

Gawande A. 1997 Feb 1. When doctors make mistakes. New Yorker 40-55.

Groopman J. 2007. How doctors think. New York: Houghton Mifflin Company.

Lawrence PF, Bell RM, Dayton MT, Hebert JC, Ahmed MI, eds. 2013. Essentials of general surgery. 5th ed. Baltimore (MD): Wolters Kluwer Health/Lippincott Williams \& Wilkin.

Meador C. 2013. Fascinomas: fascinating medical mysteries. North Charleston (SC): CreateSpace Independent Publishing Platform.

Pestana C. [2015]. Dr. Pestana's surgery notes: top 180 vignettes for the surgical wards. 2nd ed. New York: Kaplan.

So you want to be a surgeon. c1996-2019. Chicago: American College of Surgeons; [accessed 2019 Apr 1]. https://www.facs.org/education/ resources/residency-search. This web page gives information about this title.

Swendiman RA, Edmondson AC, Mahmoud NN. 2019. Burnout in surgery viewed through the lens of psychological safety. Ann Surg 269:234-5.

Tribble C. 2016. A practical minded obsession with the possibility and consequence of failure. Heart Surg Forum 19:E1-4.

Tribble C. 2016. Gimme 3 Steps: (with a nod to an American rock song from the 1970s). Heart Surg Forum 19:E80-1.

Tribble C. 2018. On becoming a surgical intern: navigating the lurch from medical school to internship. Heart Surg Forum 21:E423-31.

Tribble C, Merrill WH. 2014. The way we talk is the way we teach. J Thorac Cardiovasc Surg 147:1155-9.

Tribble C, Merrill WH. 2016. In your own words: toward a more perfect union of patient care and education. Ann Thorac Surg 101:837-40.

\section{ADDITIONAL RECOMMENDED READING AND RESOURCES FOR STUDENTS ON SURGERY CLERKSHIPS}

Elefteriades JA, Tribble C, Geha AS, Siegel M, Cohen LS. 2012. The house officer's guide to ICU care: fundamentals of management of the heart and lungs. Minneapolis: Cardiotext Publishing.

Meador C. 1992. A little book of doctor rules. Philadelphia: Hanley \& Belfus, Inc. 
Pestana C. 2000. Fluids and electrolytes in the surgical patient. Philadelphia: Lippincott Williams \& Wilkins.

Boesch P. 2018 May 24. Qstream helps innovate surgery clerkship for third year medical students, improving final test scores for participants. Burlington (MA): Qstream, Inc.; [accessed 2019 Apr 1]. https://qstreamhealthcare.com/blog/2018/05/ qstream-innovates-surgery-clerkship-medical-students/.
O'Hare JA. 2018. Twelve blessings for a surgeon. JAMA 320:2603.

Silen W. 2010. Cope's early diagnosis of the acute abdomen. New York: Oxford University Press.

Tribble C. 2016. Always keep your clothes in the car. Heart Surg Forum 19:E237-40.. 